\title{
Water Production Yield of an Atmospheric Water Generator during Summer Season in South Africa
}

\author{
Palesa Mkabane, Elvis Fosso-Kankeu, Ali R Al Alili, Frans Waanders and Hemant Mittal
}

\begin{abstract}
Atmospheric water harvesting is an alternative water source in South Africa during further forecasted drought seasons ahead, including the current overwhelmed traditional water sources. The use of atmospheric water generators (AWGs) in South Africa is being explored as a substitute during an emergency or planned downtimes on water infrastructure. The AWG operates by way of distillation. It captures water vapour from the air and channels it towards an evaporation system in a sanitary environment before it liquefies and is exposed to pollution. Atmospheric water generators are one of the first in South Africa to be utilised toward optimisation to clean water from water vapour. It is effectively a mechanical clean process though it is costly, it can provide sufficient clean water. A case study conducted during the summer period in South Africa showed that a maximum of $7000 \mathrm{~L}$ of water can be recovered from an AWG on a daily basis.
\end{abstract}

Keywords - Atmospheric Water Generators; Water Vapor; Psychrometric; Evaporation; Water Production.

\section{INTRODUCTION}

It is forecasted that by the year 2025, 3 billion people, scattered over 52 countries, will experience water shortages [1]. In 2015, South Africa had the lowest amount of rainfall since records began in 1904. While future climate predictions continue to worsen, alternative crops, water sources and methods of electricity production will need to be considered; failing to do so will result in increased food, energy, and water insecurity [2]. Access to clean water is a growing challenge globally, especially in areas where natural freshwater is not available, and communities rely on processes like desalination for clean water. Methods for producing freshwater must be equal to or more cost-effective than clean drinking water from other sources at the point of use. Atmospheric water generation is one promising option for producing clean drinking water from atmospheric air [3].

Therefore, this paper discusses atmospheric water harvesting during the summer season, as an alternative water source in South Africa; as both the source of choice especially with the prevailing drought conditions upon the country and pollution of

Palesa Mkabane, Elvis Fosso-Kankeu and Frans Waanders, Water Pollution Monitoring and Remediation Initiatives Research Group in the School of Chemical and Minerals Engineering of the North-West University, Potchefstroom-South Africa.

Ali R Al Alili and Hemant Mittal Department of Mechanical Engineering, Khalifa University of Science and Technology, Sas Al Nahkl Campus, Abu Dhabi, United Arab Emirates. freshwater due to industrialisation and urbanisation. The National Water Act forecasted further water shortages in the future due to drought and increased demand to access to clean water [4]. South Africa is a semi-arid and water-scarce country and has become worse recently with the droughts. Therefore, water usage needs to be well managed and protected against pollution, uncontrolled use and wastage. Water resources continue to deplete due to high and rapid increase of population growth while industrialisation water demands continue to grow. Acid mine water drainage pollution is mentioned as the leading pollution contributor in the country with a huge storage footprint as artificial dams containment [5-9].

The pollution chain continues with rainfall erosion which redirects the polluted water elsewhere where it ends up mixing with irrigation water or just flowing directly on to the crops; consequently, creating detrimental diseases for both humans and animals [10].

Atmospheric water supply can be considered as cleaner resource compared to the traditional streams from dams and rivers. That is mainly because atmospheric air pollution impact is dependent on the activities of the particular area with particulates presence within the atmosphere at a particular time. There are no South African citations on atmospheric water harvesting which motivates researchers and investors to explore the field as an opportunity of economic growth moving into the future. The following are some of the atmospheric water harvesting benefits when compared to traditional water supply resources:

- When ambient temperatures are very high, the water rises and concentrates as vapour in the air, which can increase harvesting.

- The process does not need the conventional known infrastructure, because of its simplicity it can be erected anywhere, and the filtration stages will depend on the air quality.

- The process is environmentally friendly as there are not by-product footprints such as sludge when compared to the traditional water treatment plants.

\section{METHOD}

The paper discusses the atmospheric water harvesting research project which involves a case study of an atmospheric water generator (AWG) based in Garankuwa that employs 
vapour compression cycle to condense water vapour from the atmosphere by cooling the atmospheric air below its dew point temperature. Then, the water is passed through multiple stages of filtration to satisfy the South African National Standards [11]. The plant is the first of this magnitude in South Africa while there is no cited research work about the technology and its viability in South Africa. These AWGs are designed to produce $10000 \mathrm{~L}$ of pure drinking water per day. They are powered by the national electricity grid with a consumption of $105 \mathrm{~kW}-\mathrm{hr}$ when on load. The AWGs do not generate any by-product except for the exhaust air after dehumidification.

The success of the AWG technology is based on the science of ambient temperature and relative humidity $(\mathrm{RH})$ of which water formation is favoured from temperatures of above $15^{\circ} \mathrm{C}$ and $\mathrm{RH}$ of above $30 \%$. As the temperature increases, the relative humidity decreases. Daily and hourly dry bulb temperature and $\mathrm{RH}$ records have been taken at the case study site since April 2020 to date in correlation to water production of the AWG. The collected water is sampled before filtration, post-filtration and post ultraviolet (UV) rays treatment and finally at ozonation stage. These samples are then sent to a South African National Accreditation of Standards (SANAS) accredited laboratory to perform analysis against South African National Standards [11] for conformance on drinking water. T

There are weekly water predictions conducted for these generators with the information given by South African Weather Service information which assists in informed decision making for water sales too as these generators are commercialised for water supply. There is also planned maintenance conducted on AWGs as stipulated by the original equipment manufacturer (OEM) on filtration systems and compression cycle equipment to ensure long term plant health of the generators.

\section{RESULTS}

The case study has proven the success of AWGs, though they have not yet performed at their maximum capacity. The highest water production has been $6700 \mathrm{~L}$ on the 30th of March 2020, as seen in Figure 1. On this particular day, temperatures were continuously about $25^{\circ} \mathrm{C}$ with a RH of $45 \%$. The OEM stipulated that temperature conditions of $27^{\circ} \mathrm{C}$ and $\mathrm{RH}$ of $60 \%$ continuously will allow these AWGs to perform at their maximum. Literature states that psychrometric guides the designer of the heating, ventilation and air conditioning (HVAC) systems in determining their absolute efficiency. In this instance, they provide a guide before generators implementation and erecting to determine their efficiencies within a particular area to ensure return on investment on production and costs.

An atmospheric water generator (AWG) is considered a system in air conditioning or refrigeration whereby conditions can employ heat transfer or mass rate changes; therefore, the thermodynamic principle of conservation of mass and energy applies, "mass is neither created nor destroyed" [12]. Control of humidity is not required by most codes in all areas, but it is for some in most geographic areas as weather patterns are key in predicting the success and the behaviour of the AWG during the life of its operation [13].

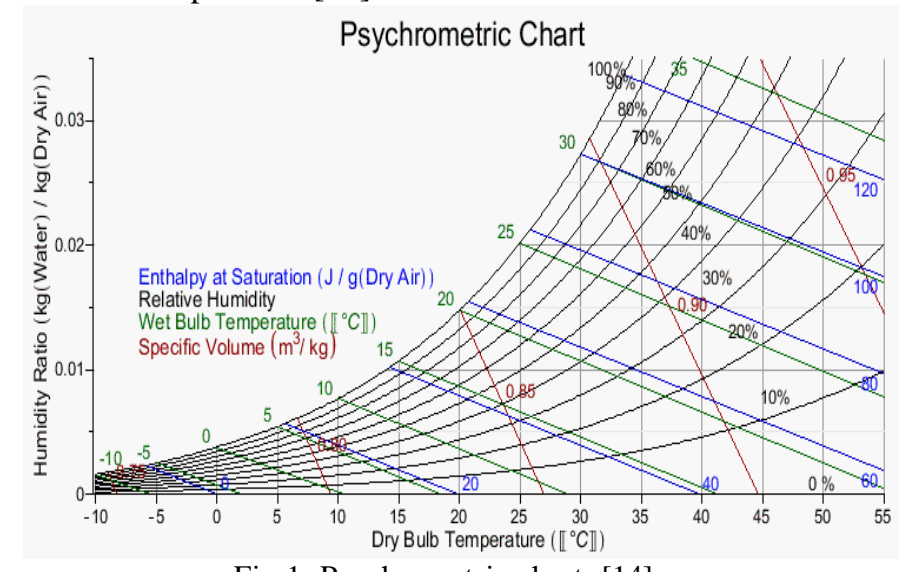

Fig 1: Psychrometric chart, [14]

The motivation for an investment of such operations is its ability to deliver water requirements as expected at the lowest cost possible. The weather patterns determine the ability of the generators to perform during South Africa's changing seasons. Uniform Mechanical Code calls for relative humidities of $50 \%-60 \%$ as suggested ranges. It has been observed that there are ambient condition limitations within this area where the AWGs are currently installed. The literature indicates that they have an opportunity to perform much better in suitable geographical areas. This statement can only be concluded if the AWGs could be exposed to a full year of all seasons.

Fig 1-4 below indicate ambient temperature, RH, and water generated for the summer months from January to April 2020. It has been discovered recently that information displayed by the graphs does not consistently support the literature that when temperature and $\mathrm{RH}$ are favourable as elaborated above, then there was no water production. For example, on the 21 st of January 2020 in Fig 1, the temperature was $22^{\circ} \mathrm{C}$ with $58 \% \mathrm{RH}$, but the water production was 0 .

Average daily temperature and $\mathrm{RH}$ readings cannot be used to forecast water production. Therefore, hourly readings need to be taken to support actual water production while forecasts need to be stipulated on an hourly basis too.

Fig 1, below is the data representation of the water generation under ambient conditions of January, the year 2020. It reveals the average temperature, average humidity and water generation. 


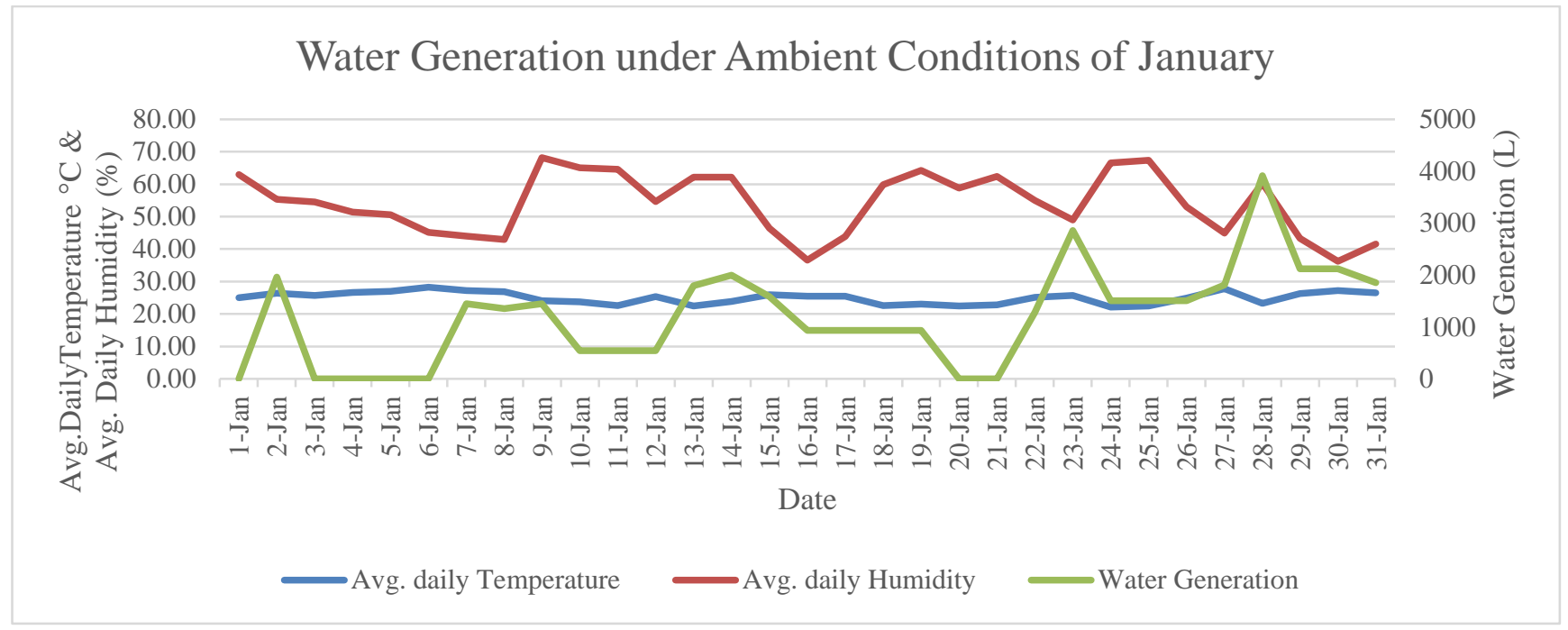

Fig 1: Water generation in January 2020

Fig 2, below is the data representation of the water generation under ambient conditions of February, the year 2020. It reveals the average temperature, average humidity and water generation.

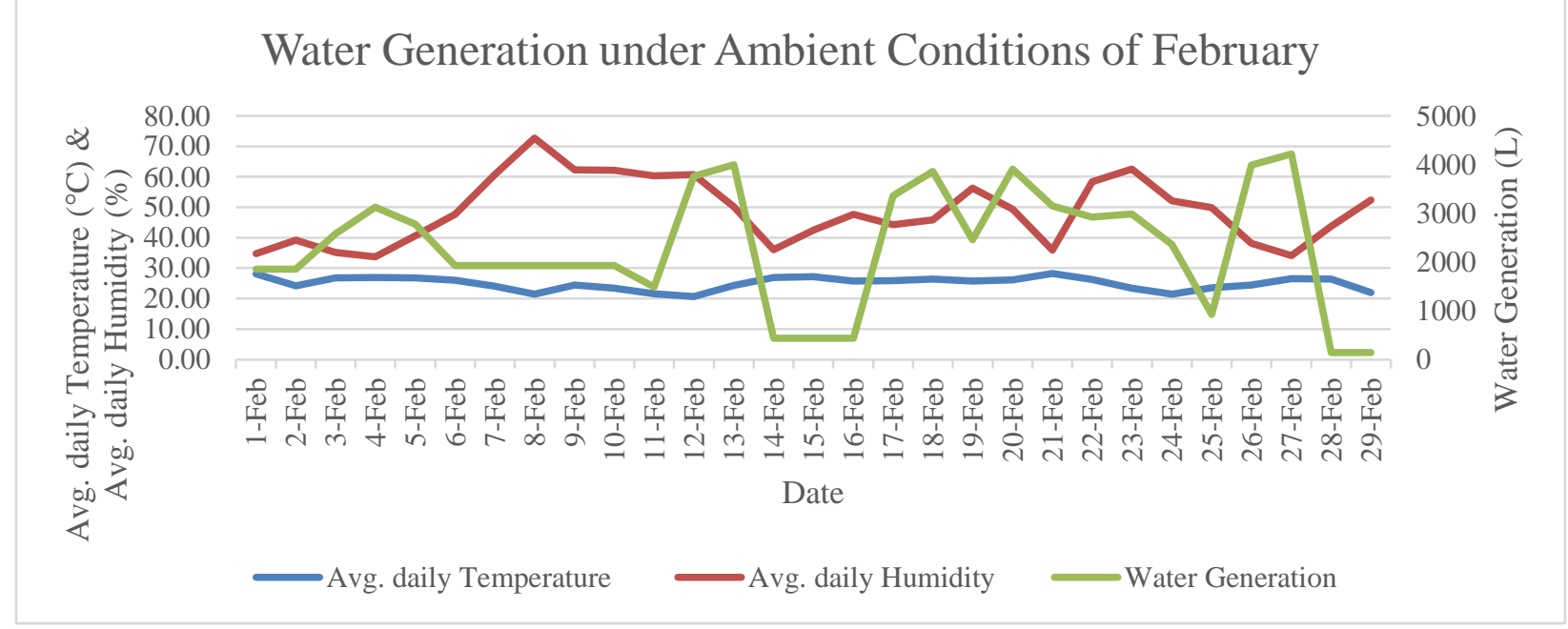

Fig 2: Water generation in February 2020

Fig 3, below is the data representation of the water generation under ambient conditions of March, the year 2020. It reveals the average temperature, average humidity and water generation.

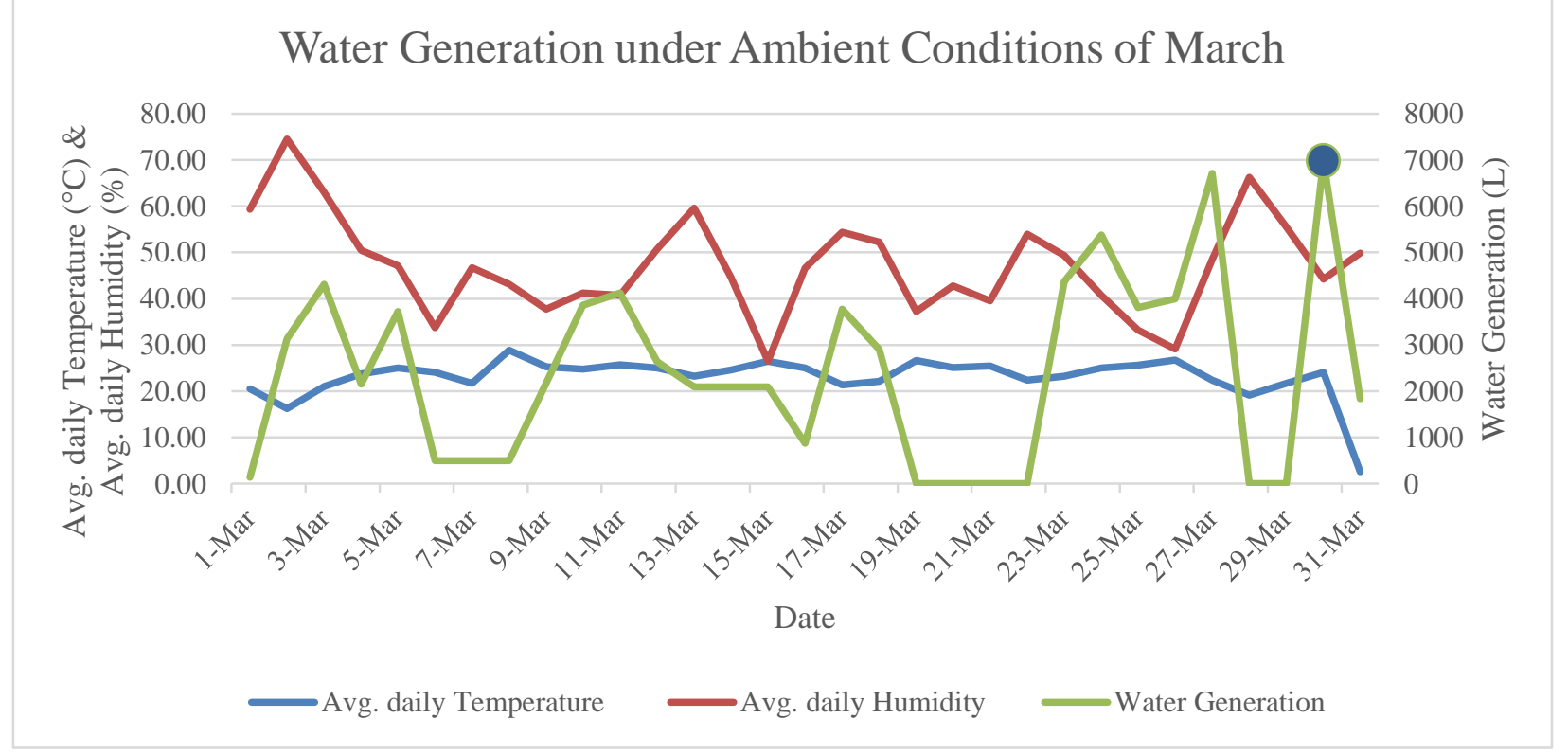


Fig 3: Water generation in March 2020

Fig 4, below is the data representation of the water generation under ambient conditions of April, the year 2020. It reveals the average temperature, average humidity and water generation.

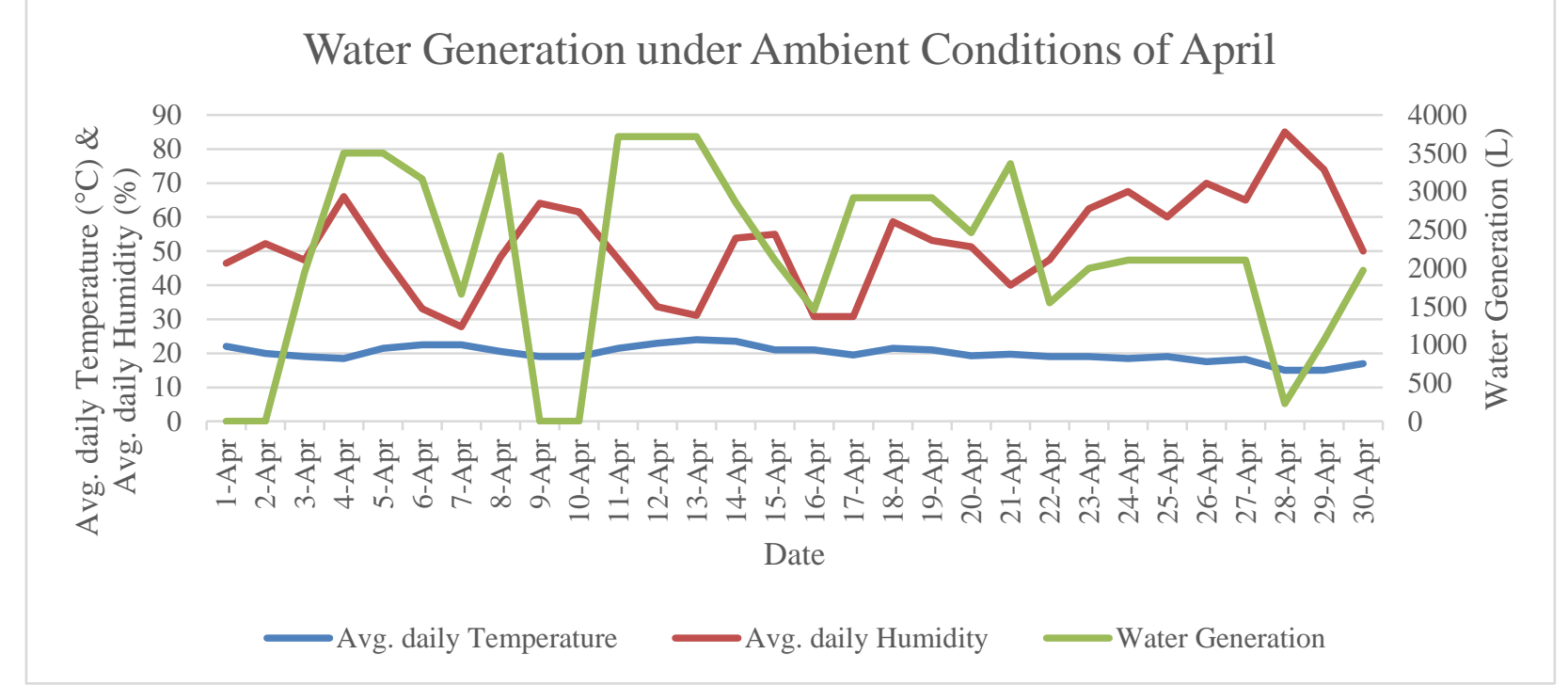

Fig 4: Water generation in April 2020

\section{CONCLUSION}

Atmospheric water harvesting through AWGs has been proven to be successful in South Africa through this case study with productivity efficiency of $67 \%$ noted in March 2020. According to literature studies, these machines could have the productivity of beyond $90 \%$ should they be based in geographical areas with much higher humidity and warmer temperatures for longer hours of the day. The technology has proven that infrastructure construction requirements which are usually needed to ensure the success of water transfer from rivers and dams could be eliminated with this type of technology whereby massive capital expenditure will be saved. Department of Water and Environmental Affairs mentioned that water demand will outstrip supply in Gauteng by 2013 and outstrip the entire country by 2025 (Water Wise Rand Water, 2020). South Africa cannot afford to build more dams and water transfer schemes as they are expensive. Operational expenditure is lower when compared to the traditional water supply infrastructure as only planned maintenance is mostly required as the generators are closed up in containers and with shielding at the top to limit the impact of sunlight and rain on the material of construction; whereas there are many kilometre arrays of long pipes and pumping stations associated with traditional water supply projects.

Most of the water stored in dams evaporate to the atmosphere and the impact is noticed during drought seasons, whereas water accumulated through AWGs is trapped from vapour and cannot escape as the plant is enclosed completely except for the air passages which allow air into the system. The disadvantage that has been noticed so far is the high energy usage by the machines. Alternatively, the solar energy source is currently being explored through this project to reduce the energy consumption of the AWG and it shall be concluded by the end of the research project.

\section{ACKNOWLEDGMENT}

Author EFK acknowledged the financial support from the National Research Foundation (NRF) in South Africa (Grant No: 120323); Any opinion, findings and conclusions or recommendations expressed in this material are those of the authors and therefore the NRF does not accept any liability in regard thereto.

\section{REFERENCES}

[1] Hoy LH. A proactive water supply shortage response plan focusing on the Green Industry in the Rand Water supply area: University of South Africa; 2009

[2] Piesse M. South Africa: Drought threatens food, energy and water security. Strategic Analysis Paper, Global Food and Water Crises Research Programme. 2016.

[3] Shannon MA, Bohn PW, Elimelech M, Georgiadis JG, Marinas BJ, Mayes AM. Science and technology for water purification in the coming decades. Nanoscience and technology: a collection of reviews from nature Journals: World Scientific; 2010. p. 337-46. https://doi.org/10.1142/9789814287005_0035

[4] Lévite H, Sally H, Cour J. Testing water demand management scenarios in a water-stressed basin in South Africa: application of the WEAP model. Physics and Chemistry of the Earth, Parts A/B/C. 2003;28(20-27):779-86 https://doi.org/10.1016/j.pce.2003.08.025

[5] Ochieng GM, Seanego ES, Nkwonta OI. Impacts of mining on water resources in South Africa: A review. Scientific Research and Essays. 2010;5(22):3351-7.

[6] Elvis Fosso-Kankeu, Alusani Manyatshe, Frans Waanders. 2017. Mobility potential of metals in acid mine drainage occurring in the Highveld area of Mpumalanga Province in South Africa: Implication of sediments and efflorescent crusts. International Biodeterioration and Biodegradation. 119: 661-670. https://doi.org/10.1016/j.ibiod.2016.09.018

[7] Elvis Fosso-Kankeu, Hemant Mittal, Frans Waanders, Suprakas Sinha Ray. 2017. Thermodynamic properties and adsorption behaviour of hydrogel nanocomposites for cadmium removal from mine effluents. Journal of Industrial and Engineering Chemistry. 48: 151-161. https://doi.org/10.1016/j.jiec.2016.12.033 
[8] E Fosso-Kankeu. 2018. Synthesized af-PFCl and GG-g-P(AN)/TEOS hydrogel composite used in hybridized technique applied for AMD treatment. Journal of Physics and Chemistry of the Earth. 105: 170-176. https://doi.org/10.1016/j.pce.2018.02.015

[9] Fosso-Kankeu Elvis and Redelinghuys Johannes. 2018. Bacterial ecology of biofilms sustaining pollution by acid mine drainage near mining areas in Mpumalanga Province - South Africa. 11th ICARD/IMWA/MWD Conference "Risk to Opportunity". 10-14 September 2018 Pretoria, South Africa. C. Wolkersdorfer, L. Sartz, A. Weber, J. Burgess, G. Tremblay.ISBN: 978-0-620-80650-3 Vol 1 (2 volumes).

[10] Bullard W. Effects of land use on water resources. Journal (Water Pollution Control Federation). 1966:645-59.

[11] SANS241-1, "South African National Standard: Drinking water. Part 1. Microbial, physical, aesthetic and chemical determinants," 2 ed. Pretoria: SABS 2015

[12] Yaqub M, Zubair SM. Capacity control for refrigeration and air-conditioning systems: A comparative study. J Energy Resour Technol. 2001;123(1):92-9. https://doi.org/10.1115/1.1349117

[13] Ludin GA, Amin MA, Aminzay A, Senjyu T. Theoretical potential and utilization of renewable energy in Afghanistan. 2016.

[14] Khan FA. A Model for Complex Heat and Mass Transport Involving Porous Media with Related Applications. 2016. 